\title{
Identification and molecular characterization of Van A-type vancomycin-resistant Enterococcus faecalis in Northeast of Brazil
}

\author{
Marinalda Anselmo Vilela, Sandra Lavareda de Souza*, Izabel Cristina Vanzato Palazzo**, \\ Joseane Cristina Ferreira**, Marcos Antonio de Morais Jr*, Ana Lúcia da Costa Darini**, \\ Márcia Maria Camargo de Morais/ ${ }^{+}$
}

Departamento de Patologia, Instituto de Ciências Biológicas *Departamento de Genética e Laboratório de Imunopatologia Keizo Asami, Universidade Federal de Pernambuco, Rua Arnóbio Marques 310, 50100-130 Recife, PE, Brasil **Departamento de Análises Clínicas, Toxicológicas e Bromatológicas, Faculdade de Ciências Farmacêuticas de Ribeirão Preto, Universidade de São Paulo, Ribeirão Preto, SP, Brasil

The isolation of vancomycin resistant enterococci (VRE) in Brazil has rapidly increased, following the world wide tendency. We report in the present study the first isolation of vancomycin resistant Enterococcus faecalis (VRE) in the Northeast of Brazil. The four VRE isolates were characterized for antimicrobial susceptibility, genotypic typing by macro restriction of chromosomal DNA followed by pulsed-field gel electrophoresis and for characterization of the Tn1546-like element and plasmid contents. The isolates showed resistance to multiple antibiotics and a single genotype profile, suggesting the dissemination of a single clone among the patients. Tn 1546 associated to genetic elements as plasmids shows the importance of infection control measures to avoid the spreading of glycopetide resistance by conjugative transfer of VanA elements.

Key words: vancomycin resistance - Enterococcus faecalis - transposable elements

Enterococci are opportunistic microorganisms, which have emerged as cause of nosocomial infection, usually in patients of long-term hospitalization (Furtado et al. 2005). In the last years, reports on vancomycin-resistant enterococci (VRE) nosocomial infections have rapidly increased in many countries worldwide, and this pathogen is now being recognized of clinical relevance.

High resistance against vancomycin and teicoplanin results from the altered affinity of this glycopeptide for its natural target, which occurs due to acquisition of Tn-1546 carrying vanRSHAX genes and elements closely related to it (Courvalin 2006). The transposon encodes the VanH dehydrogenase that reduces pyruvate to D-lac, and the VanA ligase that catalyzes the formation of an ester bond between D-ala and D-lac. The resulting D-ala-D-lac depsipeptide replaces the $\mathrm{D}$-ala- $\mathrm{D}$-ala dipeptide in peptidoglycan synthesis, a substitution that decreases the affinity of the molecule for the antibiotic glycopeptides (Courvalin 2006).

In Brazil, the first VRE isolated occurred in 1996 (Dalla Costa et al. 1998) and many cases have been described thereafter (Zanella at al. 1999, 2003, Dalla Costa et al. 2000, Cereda et al. 2001, Reis et al. 2001, Almeida et al. 2004, Camargo et al. 2004, Furtado et al. 2005). However, those studies were restricted to the Southeast, Central, and South regions of Brazil. Nevertheless, the rapid spreading sug-

Financial support: Facepe (PPP-006/2003), Pró-Reitoria de Pesquisa, USP (2004.1.25515.1.8)

${ }^{+}$Corresponding author: camargo@icb.upe.br

Received 21 Februarey 2006

Accepted 15 August 2006 gested that novel cases should soon be detected in Northern and North regions as well. In this report we describe the isolation of four VRE in Recife, state of Pernambuco, Northeast of Brazil, which seems to be the first report in this region.

\section{MATERIALS AND METHODS}

Bacterial strains and clinical features - The VRE isolates $(n=4)$ studied were isolated in 2004, from patients of a teaching university hospital (Hospital Universitário Oswaldo Cruz - HUOC), located in the city of Recife, Pernambuco, Northeast of Brazil. The hospital has 342 beds and belongs to the State University of Pernambuco. The bacteria were stored at $-80^{\circ} \mathrm{C}$. The VRE isolates were collected from four patients at post-surgical period, after being submitted to gastroplastic surgery (one patient), exploratory laparatomy (one patient), and liver transplantation (two patients). They remained in the hospital from 41 to 60 days at intensive care unit (ICU), sharing 10 days all together at the same hospital sector. Two patients died, one of them presenting positive blood culture for VRE.

Isolates were presumptively identified as enterococci by colonial morphology, Gram's stain, the absence of catalase production, the presence of pyrrolidonylarylamidase by hydrolysis of L-pyrrolidonil- $\beta$-naphthylamide (Becton, Dickinson \& Co., Franklin Lakes, NJ), tolerance to $6.5 \%$ sodium chloride, ability to grow at $10^{\circ} \mathrm{C}$ and $45^{\circ} \mathrm{C}$, growth on bile-esculin agar, with esculin hydrolysis, and growth on tellurite agar.

Susceptibility testing - Screening for antibiotic resistance was performed by disk diffusion method on MuellerHinton agar according to "Clinical and Laboratory Standard Institute" guidelines (CLSI 2005) for the following antimicrobial agents: chloramphenicol, penicillin, erythromycin, vancomycin, teicoplanin, ciprofloxacin, gen- 
tamycin, streptomycin, ampicillin, linezolide, and tetracycline. The minimum inhibitory concentration (MIC) for vancomycin and teicoplanin was determined by Etest.

The control strains used in this work were Enterococcus casseliflavus NCTC 12361, E. faecium NCTC 7171, E. faecalis NCTC 775, E. gallinarum NCTC 12359, E. faecium BM 4147 vanA genotype, E. faecium BM4105, E. faecalis JH2-2, and S. aureus ATCC 25923 for MIC assays.

Molecular identification of VRE isolates - Bacterial DNA was extracted by rapid alkaline lysis method and used as template in amplification reactions according to Depardieu et al. (2004). Briefly, the identification of $E$. faecalis isolates was done by the amplification of the 475 bp fragment corresponding to the $d d l_{E \text {. faecalis }}$ gene using the primers DD13(+) (5'-CACCTGAAGAAACAGGC-3') and DD3-22(-) (5'- ATGGCTACTTCAATTTCACG-3'). Control amplification was performed using the $E$. faecalis JH2-2 reference strain. Additionally, DNA of the E. faecium reference strains BM4105 and BM4147 were amplified with the primers FAC1-1(+) (5'-GAGTAAATCACTGAACGA3') and FAC2-1(-) (5'-CGCTGATGGTATCGATTCAT-3') to produce the 1091-bp species-specific fragment corresponding to the $d d l_{\text {E. faecium }}$ gene.

Detection of the vanA gene - The bacterial DNA samples were used for the detection of vanA gene by the use of the primers EA1(+) (5'-GGGAAAACGACAATTGC3') and EA2(-) (5'-GTACAATGCGGCCGTTA-3') according to Depardieu et al. (2004).

Genotyping analysis - The bacterial isolates were submitted to two different approaches: polymerase chain reaction (PCR)-fingerprinting and pulsed-field gel electrophoresis (PFGE). For PCR-fingerprinting, total genomic DNA of the four VRE isolates was obtained by alkaline lysis method (Sambrook et al. 1989) and used as template for the amplification of ITS-rDNA sequences with the primers KT03(16S) (5'-TTGTACACACCGCCCGTCA-3') and KT04(23S) (5'- GGTACCTTAGATTGTTTCAGTTC-3') according to Kostman et al. (1992). Additionally, PCR analysis of the tRNA-encoding sequences used the primers T5A (5'-AGTCCGGTGCTCTAACCAACTGAC) and T3B (5'-AGGTCGCGGGTTCGAATCC-3') according to Welsh and McClelland (1991). For both markers E. faecalis ATCC 12953 was used as reference strain. The resulting amplification fragments were separated on $1.2 \%$ agarose gel at 7 V.cm ${ }^{-1}$ in 0.5 X TBE buffer.

PFGE analyses of SmaI-digested bacterial DNA was performed in Gene Navigator apparatus (Amersham, Upsalla, Sweden) at $180 \mathrm{~V}$ for $25 \mathrm{~h}$, at $7^{\circ} \mathrm{C}$, as described previously by Campanile et al. (2003). The equipment was adjusted for pulses of $20 \mathrm{~s}$ for $10 \mathrm{~h}, 8 \mathrm{~s}$ for $10 \mathrm{~h}$, and $3 \mathrm{~s}$ for $5 \mathrm{~h}$. DNA banding patterns were visualized at UV light after staining with ethidium bromide. The isolates clonality was judged using previously described criteria (Tenover et al. 1995) by comparing visually the banding patterns of samples that have run together in the same gel.

Amplification and characterization of Tn1546-like elements - Amplification of Tn1546- like elements and vanRSHAX regions was performed by Long-PCR (L-PCR) according to the method described by Palepou et al. (1998). Briefly, total genomic DNA of the strains was extracted as described by Pitcher et al. (1989) and used as templates for PCR with the single primer P1 (5'- GGAA AATGCGGATTTACAACGCTAAG-3'), complementary to the transposon-flanking inverted repeats, using the Expand Long Template PCR System (Roche, Germany) to produce a 10,800-bp fragment. Subsequently, the amplified Tn1546-like element was the template for L-PCR of vanRSHAX genes using primers P2 (5'- AGACAAGT CTGAGATTGACCTTGCC-3') and P3 (5'- ATATGCTT GAAACCCACTGTTTTCC-3') to produce a 4400-bp fragment. Primary PCR products were directly analyzed on $1 \%$ agarose gel or digested overnight with ClaI for the entire Tn1546-like elements or with DdeI for the vanRSHAX genes (Palepou et al. 1998). The resulting fragments were separated by electrophoresis through $2 \%$ agarose gels.

Plasmid profiles - Plasmids DNA were extracted by alkaline lysis (Birnboim and Doly 1979), and the profiles were compared after electrophoresis on $1 \%$ agarose gels. The size of plasmids were measured by comparing their mobility with those of plasmids of known size as the ones from E. coli V517 (NCTC 50193) and E. coli 39R861 (NCTC 50192).

Southern hybridization and digestion with EcoRI Plasmids were digested with EcoRI, transferred onto nylon membrane and also hybridized with digoxigenin-labelled probe for the vanA gene. Plasmid DNA was Southern blotted onto nylon membranes (Hybond-N+, Amersham, Upsalla, Sweden) with a VacuGene vacuum blotting apparatus (Amersham), and the blots were hybridized with digoxigenin-labelled vanA-specific probe. This probe was prepared by PCR from genomic DNA of the strain E. faecium BM 4147 with primers and conditions previously described (Coque et al. 1998) except that the concentration of dTTP $(10 \mathrm{mM})$ was reduced and digoxigenin-labelled dUTP $(1 \mathrm{mM})$ was included. Hybridization was performed according to the DIG System user's guide for filter hybridization (Roche, Germany).

\section{RESULTS}

Bacterial identification - The isolates were confirmed for the species $E$. faecalis by conventional biochemical tests and subsequently by the amplification of the speciespecific 475 bp fragment of $d d l$ gene (Fig. 1).

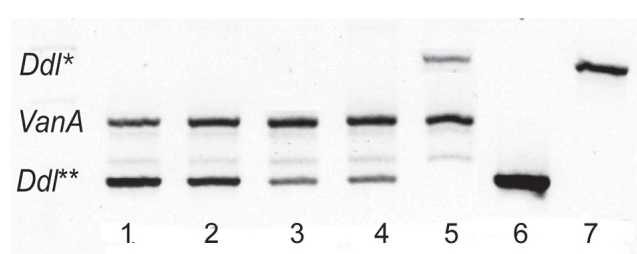

Fig. 1: bacterial identification by specific polymerase chain reaction (PCR) for $d d l$ gene of Enterococcus faecium (Ddl*) and E. faecalis ( $\left.D d l^{* *}\right)$ and PCR detection of the vanA gene. Lanes - 1-4: clinical isolates of E. faecalis Ef-1 to Ef-4; 5: E. faecium BM4147 (vanA positive, reference strain); 6: E. faecalis JH2-2 (susceptible, reference strain); 7: E. faecium BM4105 (susceptible, reference strain). 
Bacterial susceptibility - The four isolates displayed the same susceptibility profiles, showing concomitant resistance to chloramphenicol, penicillin, erythromycin, teicoplanin, ciprofloxacin, and tetracycline. It was also detected high level of aminoglicoside resistance (gentamicin and streptomycin). On the other hand, all the isolates were susceptible to ampicillin and linezolide in disk diffusion tests. MIC for vancomycin and teicoplanin was higher than $256 \mu \mathrm{g} / \mathrm{ml}$.

Van gene detection - All isolates harbored the vanA gene as demonstrated by PCR analysis (Fig. 1), which confirmed the phenotype of resistance to both vancomycin and teicoplanin.

Genotyping analysis of chromosomal DNA - Genetic analysis by rDNA and tDNA markers showed the same pattern for all the isolates and for the reference strain (Fig. 2), which was corroborated by the identical PFGE patterns (Fig. 3). It indicates the clonality among these isolates.

Detection of $\mathrm{Tn} 1546$-like elements and plasmids The presence of the Tn1546-like elements harboring the vanRSHAX genes was confirmed for all VRE isolates by L-PCR method (Fig. 4a). Moreover, enzymatic digestion of this fragment with ClaI and DdeI showed the expected results for the complete sequence of the transposon. All results indicated the integrity of the Tn1546 in these VRE isolates.

The plasmid analysis showed the presence of a $70 \mathrm{~kb}$ plasmid DNA for all isolates (Fig. 4b) and Southern hy-

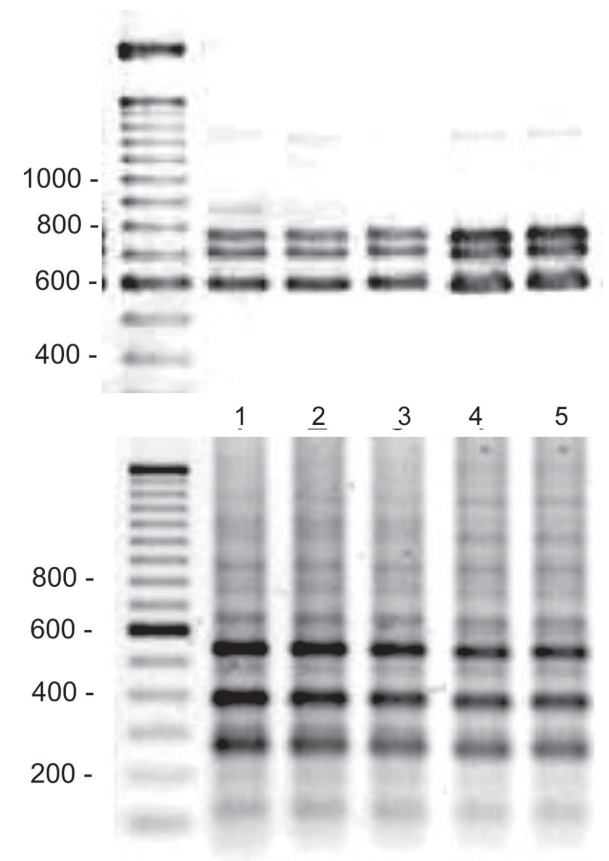

Fig. 2: molecular analysis of the clinical isolates of Enterococcus faecalis by tDNA (upper) and rDNA (lower) polymerase chain reaction-based methods. The amplification patterns correspond to E. faecalis ATCC 12953 reference strain (lane 1) and E. faecalis Ef-1 to Ef-4 (lanes 2-5). The $100 \mathrm{bp}$ ladder DNA was used as marker.

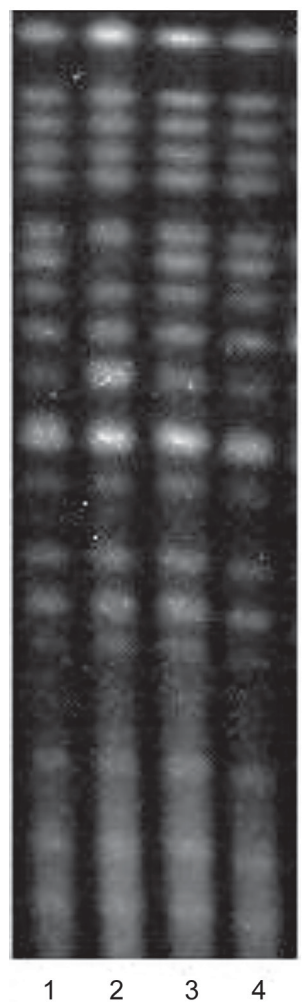

Fig. 3: pulsed field gel electroforesis patterns after SmaI digestion of total DNA extracted from the vancomycin resistant Enterococcus faecalis strains. Lanes 1-4: clinical isolates of Enterococcus faecalis Ef-1 to Ef-4.

bridization revealed that those plasmids harbored copies of the van A gene (Fig. 4c). Positive vanA hybridization in the chromosomal DNA band in the plasmid extractions suggests a second copy of the Tn1546. In addition, Southern hybridization showed positive hybridization to the $4.3 \mathrm{~kb} E c o$ RI fragment of these plasmids with vanA probe (data not shown).

\section{DISCUSSION}

The emergence of vancomycin resistant enterococci changed the clinical relevance of enteroccocal infections through the world. In Southeast of Brazil, the isolation of such pathogens is more frequent, since many works have been reporting their rapid emergency (Dalla Costa et al. 2000, Zanella at al. 1999, 2003, Reis et al. 2001, Cereda et al. 2001, Almeida et al. 2004, Furtado et al. 2005). In the present study we describe the first isolation of a vancomycinresistant E. faecalis in Recife, Northeast Brazil, indicating that the vancomycin resistance might be rapidly spreading through the country. Due to the phenotype of high level of vancomycin resistance, the isolates were tested for the presence of specific resistance genes ( $v a n A$ and van B) by PCR, which indicated the presence of the van $A$ gene. The isolates investigated showed $100 \%$ of susceptibility to ampicillin, similarly to the results reported by Reis et al. (2001). However, they were highly resistant to aminoglicosides, limiting thus the success of such asso- 


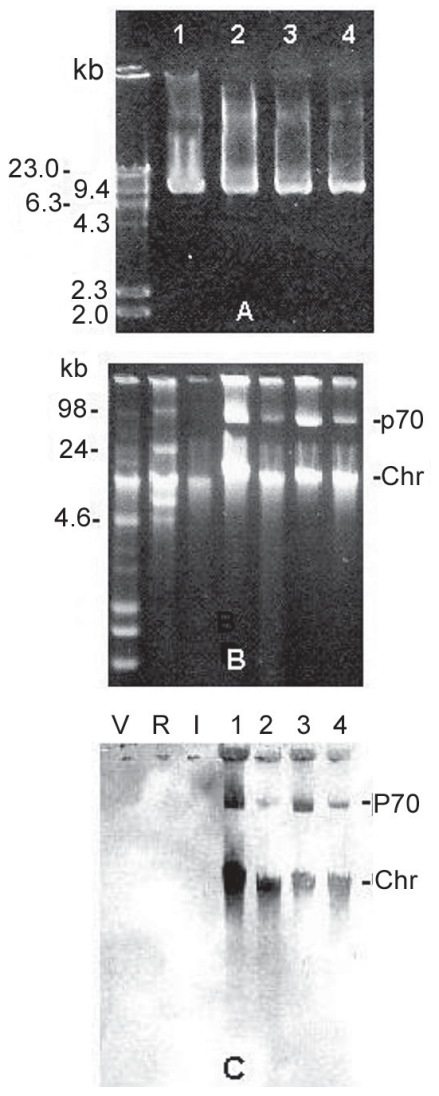

Fig. 4: molecular analysis of Tn1546 element and plasmid DNA in vancomycin resistant Enterococcus faecalis (VRE) isolates. A: longpolymerase chain reaction (PCR) amplification of $\mathrm{Tn} 1546$ with DNA samples from E. faecalis isolates (lines 1 to 4). Molecular size marker $\lambda$ DNA/HindIII fragments (Gibco Life Technologies, US) (line M); B: plasmid analysis of the VRE isolates (line 1 to 4). Control samples for known sized plasmids Escherichia coli V517 (line V) and E. coli 39R861 (line R), and negative plasmid strain $E$. faecalis JH2 (line I) are shown; C: Southern blot from the corresponding to panel (B) showing hybridization with the vanA gene probe. Chromosome DNA (Chr) and the $70 \mathrm{~Kb}$ plasmid (p70) are shown.

ciated antibiotic therapy. The concomitant resistance observed to chloramphenicol, penicillin, erythromycin, teicoplanin, ciprofloxacin, and tetracycline confirms that resistance of enterococci to multiple antibiotics is common, as also observed by Panesso et al. (2002). Linezolide was highly effective against all the isolates, indicating it as an appropriate therapeutic option.

The vanA gene cluster has been reported associated to $\operatorname{Tn} 1546$ or related elements, which are carried by plasmids. The localization of vanA gene in a plasmid DNA and the integrity of the Tn 1546 showed by VRE isolates studied are in agreement with published data (Arthur et al. 1996). Also, the integrity of Tn1546-like elements showed by Brazilian VREs studied so far (Palazzo et al. 2006) and the isolates of this study produced an important epidemiological data about the dissemination of Tn1546-like elements in Brazil. The presence of vanA gene in mobile DNA elements, such as plasmid carrying transposons, indicates that this resistance mechanism could rapidly spread by conjugation between VRE and vancomycinsensitive enterococci (VSE) strains at appropriate intestinal environment of the patients (Fines et al. 1999), leading to spreading of glycopeptide resistance.

In connection to the resistance evolution, the use of DNA-based typing methods offers high sensitivity and specificity at two levels: species identification and strain discrimination. The amplification of the specie-specific $d d l$ gene fragment (Dutka-Malen et al. 1995) confirmed the species identification of the isolates. Additionally, PCR rDNA and tDNA genotyping succeeded in identifying the isolates at species level when comparing to reference strains, as previously described by PCR-tDNA for Enterococci (Baele et al. 2000). PFGE analysis has been long used for monitoring the dissemination of VRE clones in different countries (Suppola et al. 1999, Duckro et al. 2005, Stampone et al. 2005). Our data on PFGE strongly suggested the dissemination of a single VRE clone among the hospitalized patients in Recife. Moreover, three isolates were originated from the same hospital sector while one isolate was from a different one. The PFGE profile observed for the E. faecalis analyzed in the present study was closely related to those found in other states of Brazil (São Paulo, Paraná, Rio Grande do Sul, and Minas Gerais), indicating a clonal spread among this specie in Brazil (Palazzo et al. 2006).

In conclusion, the VRE cases in Recife were result of a single clone that disseminated for different patients and hospital environments. The Tn1546 integrity and vanA gene associated to plasmids may facilitate the dissemination of vancomycin resistance among enterococci. One important implication of VRE infections is that the antibiotic therapy is now compromised. The results pointed out for the importance of the rational use of vancomycin and the execution of infection control measures as well.

\section{ACKNOWLEDGMENTS}

To Mr Carlos LN Cabral for his help in bacterial isolation and to Dr Patrice Courvalin and Dr Florence Depardieu for their kindly contribution to van genes detection and bacterial identification.

\section{REFERENCES}

Almeida RT, Filho MR, Silveira CAN, Rodrigues IP, Filho JE, Nascimento RS, Ferreira II RF, Moraes LMP, Boelens H, Belkum AV, Felipe MSS 2004. Molecular epidemiology and antimicrobial susceptibility of Enterococci from Brazilian Intensive Care Units. Braz J Infect Dis 8: 197-205.

Arthur M, Reynolds P, Courvalin P 1996. Glycopeptide resistance in enterococci. Trends Microbiol 4: 401-407.

Baele M, Baele P, Vaneechoutte M, Storms V, Butaye P, Devriese LA, Verschraegen G, Gillis M, Haesebrouck F 2000. Application of tRNA intergenic spacer PCR for identification of Enterococcus species. J Clin Microbiol 38: 4201-4207.

Birnboim H C, Doly J 1979. A rapid alkaline extraction procedure for screening recombinant plasmid DNA. Nucleic Acids Res 7: 1513-1523.

Camargo ILBC, Del Peloso PF, da Costa Leite CF, Goldman GH, Darini ALC 2004. Identification of an unusual VanA element in glycopeptide-resistant Enterococcus faecium in 
Brazil following international transfer of a bone marrow transplant patient. Can J Microbiol 50: 767-770.

Camargo ILBC, Zanella RC, Brandileone MC, Pignatari AC, Goldman GH, Woodford N, Darini AL 2005. Occurrence of insertion sequences within the genomes and Tn1546-like elements of glycopeptide-resistant enterococci isolated in Brazil, and identification of a novel element, ISEfa5. Int $J$ Med Microbiol 294: 513-519.

Campanile F, Bartoloni A, Bartalesi F, Borbone S, Mangani V, Mantella A, Nicoletti G, Paradisi F, Russo G, Strohmeyer M, Stefani S 2003. Molecular alterations of VanA element in vancomycin-resistant enterococci isolated during a survey of colonized patients in an Italian intensive care unit. Microb Drug Resist 9: 191-199.

Cereda RF, Sader HS, Jones RN, Sejas L, Machado AM, Zanatta YP, Rego STMS, Medeiros EAS 2001. Enterococcus faecalis resistant to vancomycin and teicoplanin (VanA phenotype) isolated from a bone narrow transplanted patient in Brazil. Braz J Infect Dis 5: 40-46.

CLSI-Clinical Laboratory Standards Institute 2005. Performance standards for antimicrobial susceptibility testing. 15th Informational Supplement M100-S15, Wayne, PA.

Coque TM, Seetulsingh P, Singh KV, Murray BE 1998. Application of molecular techniques to the study of nosocomial infections caused by enterococci. In N Woodford, AP Johnson (eds), Molecular Bacteriology: Protocols and Clinical Applications, Humana Press, New Jersey, p. 469-493.

Courvalin P 2006. Vancomycin resistance in Gram-positive cocci. Clin Infect Dis 42 (Supp. 1): S25-42.

Dalla Costa LM, Reynolds PE, Souza HAPHM, Souza DC, Palepou MFI, Woodford N 2000. Characterization of a divergent vanD-type resistance element from the first glycopeptide-resistant strain of Enterococcus faecium isolated in Brazil. Antimicrob Agents Chemother 44: 3444-3446.

Dalla Costa LM, Souza DC, Martins LTF, Zanella RC, Bandilleone MC, Bokerman S, Sader HS, Souza APHM 1998. Vancomycin-resistant Enterococcus faecium: first case in Brazil. Braz J Infect Dis 2: 160-163.

Depardieu F, Perichon B, Courvalin P 2004. Detection of the van alphabet and identification of enterococci and staphylococci at the species level by multiplex PCR. J Clin Microbiol 42: 5857 - 5860.

Duckro AN, Blom DW, Lyle EA, Weinstein RA, Hayden MK 2005. Transfer of vancomycin-resistant enterococci via health care worker hands. Arch Intern Med 165:302-307.

Dutka-Malen S, Evers S, Courvalin P 1995. Detection of glycopeptide resistance genotypes and identification to the species level of clinically relevant enterococci by PCR. J Clin Microbiol 33: 24-27.

Fines M, Perichon B, Reynolds P, Sahm DF, Courvalin P 1999 VanE, a new type of acquired glycopeptide resistance in Enterococcus faecalis BM4405. Antimicrob Agents Chemother 43: 2161-2164.

Furtado GHC, Martins ST, Coutinho AP, Wey SB, Medeiros EAS 2005. Prevalence and factors associated with rectal vancomycin-resistant enterococci colonization in two intensive care units in São Paulo, Brazil. Braz J Infect Dis 9: 6469.

Kostman JR, Edlind TD, Lipuma JJ, Stull TL 1992. Molecular epidemiology of Pseudomonas cepacia determined by polymerase chain reaction. J Clin Microbiol 30: 2084- 2087.

Palazzo ICV, Camargo IBC, Zanella RC, Darini ALC 2006. Evaluation of clonality on enterococci isolated in Brazil carrying Tn1546-like elements associated to vanA plasmids FEMS Microbiol Lett 258: 29-36.

Palepou M-FI, Adebiyi A-MA, Tremlett CH, Jensen LB, Woodford N 1998. Molecular analysis of diverse elements mediating VanA glycopeptide resistance in enterococci. $J$ Antimicrob Chemother 42: 605-612.

Panesso D, Ospina S, Robledo J, Vela MC, Peña J, Hernández O, Reyes J, Arias C 2002. First characterization of a cluster of VanA-type glycopeptide-resistant Enterococcus faecium, Colombia. Emerg Infect Dis 8: 961-965.

Pitcher DG, Sanders NA, Owen RJ 1989. Rapid extraction of bacterial genomic DNA with guanidium thiocyanate. Lett Appl Microbiol 8: 151-156.

Reis AO, Cordeiro JC, Machado AM, Sader HS 2001. In vitro antimicrobial activity against vancomycin-resistant enterococci isolated in Brazilian hospitals. Braz J Infect Dis 5: 243-251.

Sambrook J, Maniatis T, Fritsch EF 1989. Molecular Cloning: A Laboratory Manual, 3rd ed., Cold Spring Laboratory Press, New York.

Stampone L, Del Grosso M, Boccia D, Pantosti A 2005. Clonal spread of a vancomycin-resistant Enterococcus faecium strain among bloodstream-infecting isolates in Italy. J Clin Microbiol 43: 1575-1580.

Suppola JP, Kolho E, Salmenlinna S, Tarkka E, Vuopio-Varkila J, Vaara M 1999. vanA and vanB incorporate into an endemic ampicillin-resistant vancomycin-sensitive Enterococcus faecium strain: effect on interpretation of clonality. $J$ Clin Microbiol 37: 3934-3939.

Tenover FC, Arbeit RD, Goering RV, Mickelsen PA, Murray BE, Persing DH Swaminathan B 1995. Interpreting chromosomal DNA restriction patterns produced by pulsedfield gel electrophoresis: criteria for bacterial strain typing. J Clin Microbiol 33: 2233-2239.

Welsh J, McClelland M 1991. Genomic fingerprints produced by PCR with consensus tRNA gene primers. Nucleic Acids Res 19: 861-866.

Zanella RC, Brandileone MC, Bokerman S, Almeida SC, Valdetaro F, Vitório F, Moreira F, Villins M, Salomão R, Pignatari AC 2003. Phenotypic and genotypic characterization of VanA Enterococcus isolated during the first nosocomial outbreak in Brazil. Microb Drug Res 9: 283-291.

Zanella RC, Valderato F, Lovgren M, Tyrrel GJ, Bokermann S, Almeida SC, Vieira VS, Brandileone MC 1999. First confirmed case of vancomycin-resistant Enterococcus faecium with vanA phenotype from Brazil: isolation from meningitis case in São Paulo. Microb Drug Resist 5: 159-162. 